\title{
El territorio de los desheredados. Asentamientos chabolistas y experiencias recientes de erradicación en Sevilla
}

\section{Francisco José Torres Gutiérrez *}

\section{Resumen}

La actualidad de la cuestión chabolista en Sevilla sugiere y permite algunas aproximaciones nuevas al fenómeno. Por un lado, asistimos, desde hace pocos años, a un nuevo proyecto de erradicación paulatina del asentamiento más representativo de los que aún quedan en pie, el del Vacie, lo cual invita a realizar una mirada retrospectiva de los resultados que han ofrecido otras intervenciones ejecutadas en los últimos años. En este sentido, atendemos a otros asentamientos de menor relevancia pero representativos de situaciones o casuísticas significativas y diversas. Entre los que permanecen vigentes, hacemos referencia a Torreblanca, Ranillas o La Paz; y entre los ya desmantelados, recordamos los de San Diego, Perdigones y Bermejales. Por otro lado, los acontecimientos protagonizados por los antiguos chabolistas de Bermejales, huidos de Polígono Sur en la primavera de 2009 a causa de un grave conflicto entre familias gitanas, pone el acento en esa otra faceta del chabolismo como fenómeno latente; una faceta que enlaza, además, con las dificultades de integración que presentan entornos urbanos muy desfavorecidos y segregados, lo que relaciona también la desigualdad urbana general y la marginación de algunos espacios con la reproducción del chabolismo, poniendo en tela de juicio las incongruentes, cuando no insuficientes respuestas políticas que se siguen aplicando frente a problemáticas ciertamente complejas como las que aquí se describe.

\section{Palabras clave}

Desigualdades urbanas; Chabolismo; Erradicación; Realojamientos; Sevilla

\section{Abstract: The Territory of the Disinherited. Slum settlements and recent eradication experiences in Seville}

Today"s situation on the issue of slums in Seville implies and allows some new approaches to the phenomenon. On one hand, in the last few years, we have witnessed a new project of the gradual eradication of the most representative settlement that remains standing, that of el Vacie, which prompts a retrospective look at the results offered by other interventions carried out in recent years. To this end, we consider other less important settlements which remain representative of the situations or of significant and diverse casuistry. Among those which remain in force, we refer to Torreblanca, Ranillas and La Paz; and among those already dismantled, we recall the settlements of San Diego, Perdigones, and Bermejales. On the other hand, the events featuring the former slum-dwellers of Bermejales, who fled from Polígono Sur in the spring of 2009 due to a major conflict between Roma families, emphasizes another facet of shanty towns as a latent phenomenon; a facet that is also linked with integration difficulties presented by very disadvantaged and segregated urban environments, which also relates overall urban inequality and marginalization of some spaces with reproduction of slum settlements, putting into question the incongruous, if not insufficient policy responses that are still applied in response to complex problems such as those described herein.

\section{Key words}

Urban inequalities; Slums; Eradication; Rehousing; Sevilla

Recibido: 10/09/2012; aceptado definitivamente: 10/09/2012

\footnotetext{
* Doctor en Geografía. Departamento de Geografía, Historia y Filosofía. Universidad Pablo de Olavide, Sevilla. C.P. 41013.E-mail: fjtorgut@upo.es
} 


\section{Introducción. Conceptualización del chabolismo, trascendencia política e implicaciones sociales y urbanas}

Desde planteamientos poco elaborados o rigurosos, suele establecerse una vinculación directa entre el chabolismo y las formas de vida que se entienden propias de minorías como la gitana. Sin embargo, es importante no refugiar argumentaciones en un determinismo cultural como éste. Es cierto que el fenómeno puede relacionarse con los mecanismos que discriminan caracteres y comportamientos étnicos diferenciados -a veces conflictivos respecto de las pautas consideradas "normalizadas"- pero parece tener principalmente su origen en la asociación que se produce entre la pobreza, la exclusión, determinadas respuestas adaptativas de estas minorías $u$ otros colectivos vulnerables, y las dificultades de acceder con tales condicionamientos a una vivienda digna e integrada en un contexto social normalizado.

De manera general, tal como expresan algunos autores, el chabolismo está relacionado estrechamente con lo que se denomina "exclusión residencial" (Cortés, 2003), y que esencialmente tiene que ver con los siguientes aspectos:

- La accesibilidad. Es decir, la posibilidad de contar con un alojamiento acorde con los recursos económicos disponibles por la persona.

- La adecuación de las características de la vivienda o alojamiento en razón de las necesidades y caracteres sociodemográficos de sus ocupantes.

- El riesgo o la seguridad de poder disfrutar de un uso estable y continuado de la vivienda; que en gran medida depende del régimen de tenencia u ocupación. Se trata por tanto de la estabilidad.

- También resulta fundamental la propia habitabilidad; es decir, la situación física y arquitec- tónica en que se encuentra la vivienda y su entorno, para que puedan cumplir unos mínimos de calidad que hagan posible una vida social integrada (ob. cit., pp. 333-334).

Desde un punto de vista político y operativo, orientado por la definición de una forma de hábitat que se debe tender a eliminar, el núcleo chabolista se define como el asentamiento humano situado al margen de la ciudad, carente de infraestructuras y con un modo de vida arraigado, donde existe un alto grado de marginalidad social. Ésta es la definición que utiliza el "Plan de Actuación en Núcleos Chabolistas en Andalucía", aprobado por Consejo de Gobierno Autonómico el 25 de noviembre de 1997 (Junta de Andalucía). Ha sido habitual considerar el "número de chabolas" que existe en un territorio como una importante variable para medir, tras su reducción o eliminación, el éxito de las políticas de vivienda. Entendiendo que una chabola puede levantarse en cuestión de horas, pensamos que resulta más juicioso preocuparse de las potenciales poblaciones y grupos chabolistas que de las chabolas y los espacios que éstas ocupan. Tal como apunta el antropólogo Juan Gamella, "En el caso de los gitanos, dado su nivel de crecimiento demográfico, su general carencia de recursos y la dificultad de acceder a nuevas viviendas, es muy probable que el problema "se reproduzca" y reaparezca en diferentes lugares donde se creía erradicado, aunque sea con nuevos rasgos" (Gamella, 1996, p. 257).

De este modo, cobra singular interés plantear esta relativa infravaloración del chabolismo como hecho material concreto y localizado, e interpretarlo no sólo a través de la constatación de que sus expresiones físicas puntuales tengan menor o mayor vigencia histórica, sino también como representación de otras desigualdades y dinámicas de segregación con las que puede considerarse indisociable; en este sentido, nos referimos a que: 
- Constituye una realidad incardinada en las desigualdades sociales urbanas desde un punto de vista global; es decir, por un lado, puede entenderse como una etapa dentro de una concepción dinámica de los procesos de integración o exclusión socio-territorial: puede serlo con un carácter "ascendente" para personas sin hogar que no encuentran cobijo o para poblaciones inmigradas con muy pocos recursos; para ellas el simple emplazamiento en la periferia de la ciudad ofrece algunas oportunidades. También puede constituir una etapa de un proceso conflictivo y de agudización de la vulnerabilidad. Así sucede en los casos de familias que se ven forzadas a abandonar sus casas a causa de reyertas entre clanes gitanos, ajustes de cuentas, movilizaciones racistas, particulares procesos de exclusión socio-residencial, etc., y que pueden acabar originando nuevos enclaves de este tipo.

- Se trata de una consecuencia de estructuras sociales y laborales que persisten, agravadas incluso por las sucesivas inflexiones económicas, y que se ven reforzadas por el distanciamiento étnico y cultural, el modelo demográfico característico, las posibilidades formativas, la estigmatización, etc. Por ejemplo, aspectos como el desarrollo de actividades insertas en la llamada economía informal (la venta ambulante, "la busca"...) constituyen usos laborales de carácter marginal o pseudomarginal de los que sólo se obtienen unas rentas de subsistencia. En paralelo y como consecuencia de la falta de oportunidades laborales, en parte también propiciada por la evolución de un sistema productivo que va copando actividades como la recogida de cartón, chatarra, muebles viejos, etc., se ha ido produciendo un alarmante incremento del tráfico de drogas en algunos núcleos (Lago, 2004, p. 750).
- En sociedades que se reconocen desarrolladas y que poseen una cierta implantación del Estado de bienestar, se convierte en un símbolo de la marginación que plantea un continuo reto institucional. Ello provoca a que se tienda a invisibilizar a través de su ocultación o dispersión o a eliminarse mediante una erradicación que, dependiendo de las medidas subsiguientes (tipo de realojo, relocalización, acompañamiento social) puede tener resultados más o menos positivos. Así observado, el fenómeno chabolista incorpora su propia percepción ciudadana y política. La ausencia de una conceptualización integral de las desigualdades urbanas -y de las conexiones entre ellas- da lugar a que la erradicación y el realojamiento no siempre culminen en una trayectoria inclusiva para sus poblaciones; es más, estas actuaciones pueden suscitar importantes conflictos vecinales en los nuevos entornos o reproducir ambientes marginales en el seno de barrios consolidados y viviendas en principio dignas. Son conocidos los casos de "chabolismo vertical".

La actualidad de la cuestión chabolista en Sevilla sugiere y permite algunas de estas aproximaciones nuevas al fenómeno. En primer lugar, asistimos a un nuevo proyecto -se espera que definitivo- de erradicación paulatina del asentamiento más representativo de los que aún quedan en pie, el del Vacie, lo cual nos invita a realizar una mirada retrospectiva de los resultados que han ofrecido otras intervenciones ejecutadas en los últimos años. En este caso principal del Vacie, señalamos los aspectos que nos parecen más conspicuos de su realidad y que pueden explicar su perpetuación y reproducción. La complejidad del fenómeno y de este caso concreto nos debe conducir a una reflexión acerca de la dialéctica existente entre el hábitat marginal y la exclusión social. 
En segundo lugar atendemos igualmente a otros asentamientos de menor relevancia pero representativos de situaciones diversas. Se presentan así algunos rasgos básicos del poblado de Torreblanca y otros pequeños asentamientos, tales como el constituido por las viviendas prefabricadas de la Avenida de La Paz -en Polígono Sur-, el emplazado junto al canal de Ranillas y otros, más o menos transitorios, también de pequeña entidad.

Como apuntábamos anteriormente, el objetivo vigente de desmantelar progresivamente El Vacie, nos incita a practicar un escueto análisis así como una interpretación de las desiguales experiencias conocidas al respecto en Sevilla: subrayamos el relativo éxito de la planteada en el área de San Diego-Los Carteros a finales de los años noventa, frente a otras operaciones que, ya acontecidas en la pasada década, consideramos cuestionables, como la de Perdigones, y claramente inaceptables, como la de Bermejales.

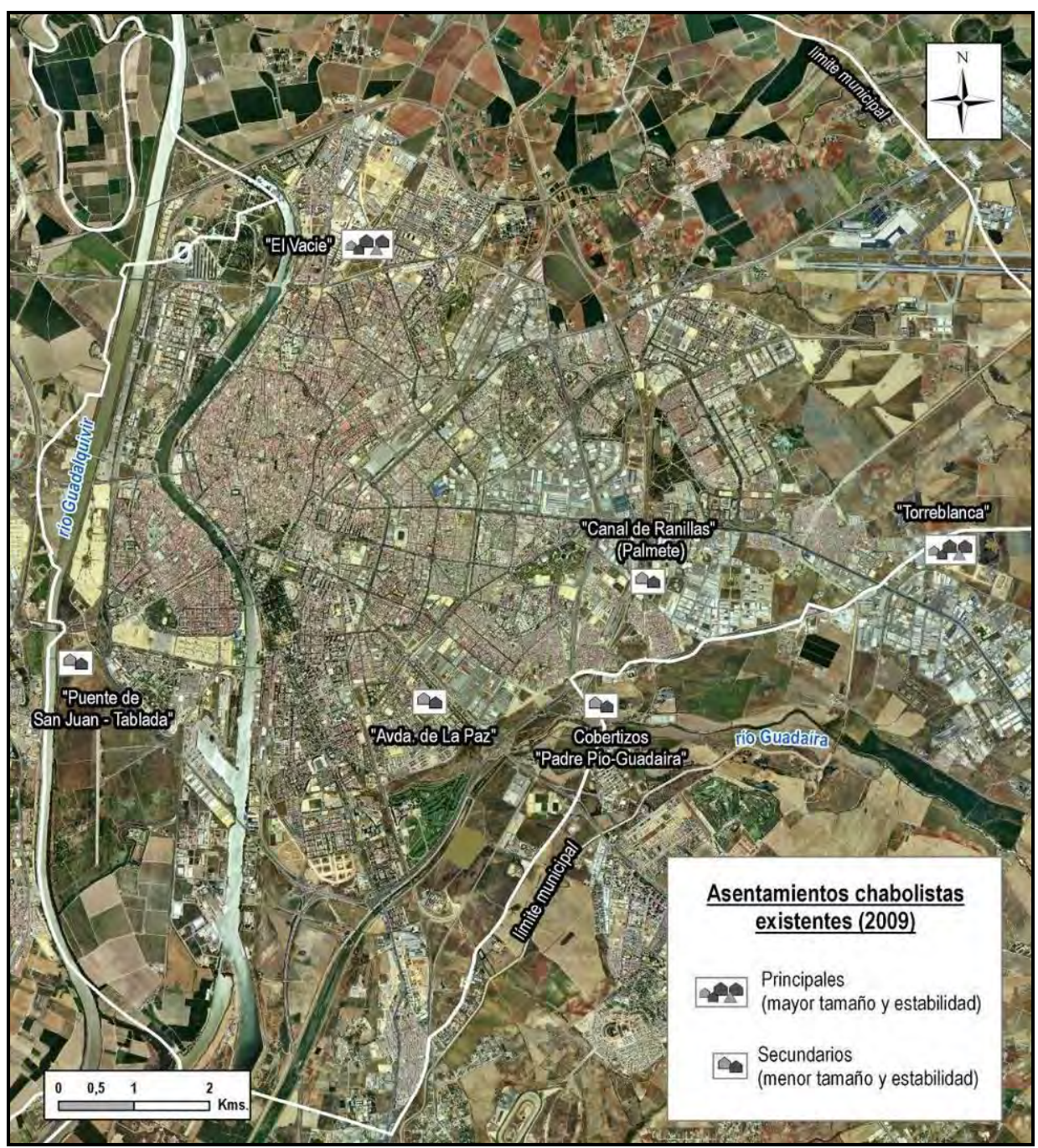

Figura 1. Distribución urbana de los asentamientos chabolistas existentes en Sevilla (2010). Fuente: Elaboración propia.

Por último, los acontecimientos protagonizados precisamente por los antiguos chabolistas de Bermejales, huidos de Polígono Sur en la primavera de 2009 a causa de un grave conflicto entre familias gitanas, pone el acento en esa otra face- ta del chabolismo como fenómeno latente y potencial; una faceta que enlaza, además, con las dificultades de integración que presentan entornos urbanos muy desfavorecidos y segregados, lo que relaciona también la desigualdad urbana 
general y la marginación de algunos espacios con la reproducción del chabolismo, poniendo en tela de juicio las incongruentes, cuando no insuficientes, respuestas políticas que se siguen aplicando frente a problemáticas ciertamente complejas como ésta.

\section{El representativo asentamiento del Vacie}

El núcleo chabolista con más entidad de los que actualmente persisten en Sevilla es El Vacie, constituyendo, sin duda, el caso más representativo de la ciudad, tanto por su larga historia como por la trascendencia política, social y urbanística que ha ido adquiriendo en los últimos años, sobre todo en el contexto de momentos electorales. El asentamiento se ha convertido en todo un símbolo de la infravivienda y de la marginalidad sevillanas y también de la desidia o desinterés de las autoridades para transformarlo o realojar a sus habitantes en entornos adecuados.

\section{Relevancia histórica y emplazamiento urbano}

La historia de este asentamiento, su arraigo espacial y sus relaciones sociales internas, son criterios que permiten definirlo como uno más de los barrios de Sevilla. Sin embargo, su fisonomía espacial y las precarias y difíciles formas de vida que implica este tipo de hábitat, aislado del entramado urbano, estigmatizado por el resto de la población e invisibilizado por las propias estadísticas censales, lo convierten no en un espacio con expectativas de transformación social in situ, sino en un asentamiento que debe ser erradicado.

Como se ha dicho, es cierto que El Vacie tiene una importante trayectoria histórica. Se trata de un espacio que ha acogido chabolas desde los años 30 del siglo $X X$, lo que lo convierte en el asentamiento de este tipo más antiguo de España y, se dice, que "de Europa", al menos esto es lo que suele exponerse en los discursos que aluden a estas raíces con la intención de resaltar su trascendencia e implicaciones a nivel político. Sin embargo, tal permanencia histórica no significa en nuestra opinión un verdadero arraigo socioterritorial de su población, ya que la evolución de este núcleo -al menos la experimentada en los últimos 20 años- ha estado sujeta a continuos cambios en su composición social y estructura espacial interior, con familias que, con cierta recurrencia, lo abandonan y otras nuevas que se instalan en él. Tal es así que la parte principal del asentamiento está formada en la actualidad por las viviendas prefabricadas levantadas por el ayuntamiento sevillano en 1992, las cuales se construyeron para realojar allí, en principio transitoriamente, a familias chabolistas que se ubicaban entonces bajo el puente de Chapina ${ }^{1}$.

No obstante lo dicho en este párrafo anterior, un análisis territorial de este tipo de hábitat marginal debe contemplar, no sólo el alcance "fenomenológico" y estructural de estos asentamientos, sino también aspectos específicos como la singularidad morfológica y las particularidades de su composición demográfica, sociocultural, etc. Ello tiene un notable interés cuando se identifican en estos poblados algunos componentes de arraigo cultural y ciudadano que favorecen las relaciones vecinales internas y los lazos sociales y económicos con el entorno. Todos estos atributos son reseñables ya que, junto a otras cualidades urbanísticas más básicas (topografía, suelos, accesos) podrían favorecer una transformación del

\footnotetext{
1 Con esta aclaración no pretendemos restar importancia al Vacie como hecho histórico, más bien creemos que es necesario delimitar qué componente de su dimensión histórica tiene realmente interés para valorar su situación actual. En este sentido, es oportuno distinguir el papel que juega su emplazamiento y situación urbana en relación a su teórica "vocación" chabolista. Asimismo, queremos subrayar la relevancia del chabolismo desde la perspectiva que apuntábamos en la presentación de este apartado, es decir, como un fenómeno que, más allá de localizaciones y expresiones físicas concretas, permanece vigente -a veces renovándoseen las estructuras sociales, culturales y económicas de la ciudad.
} 
hábitat en su propio lugar y desde su propia comunidad.

En principio, el propio emplazamiento urbano del Vacie, parece haber jugado un papel importante en la consolidación de su poblado, ya que, si bien fue eliminado parcial o completamente en determinados momentos del siglo $\mathrm{XX}$, siempre ha vuelto a reaparecer en el mismo sitio poco tiempo después. Su historia y contexto urbano, tal como puede verse en la Figura 1, nos permite apreciar la permanencia de este núcleo de chabolas en un lugar que ha visto cómo se transformaba significativamente su entorno y con ello su situación urbana y su percepción.

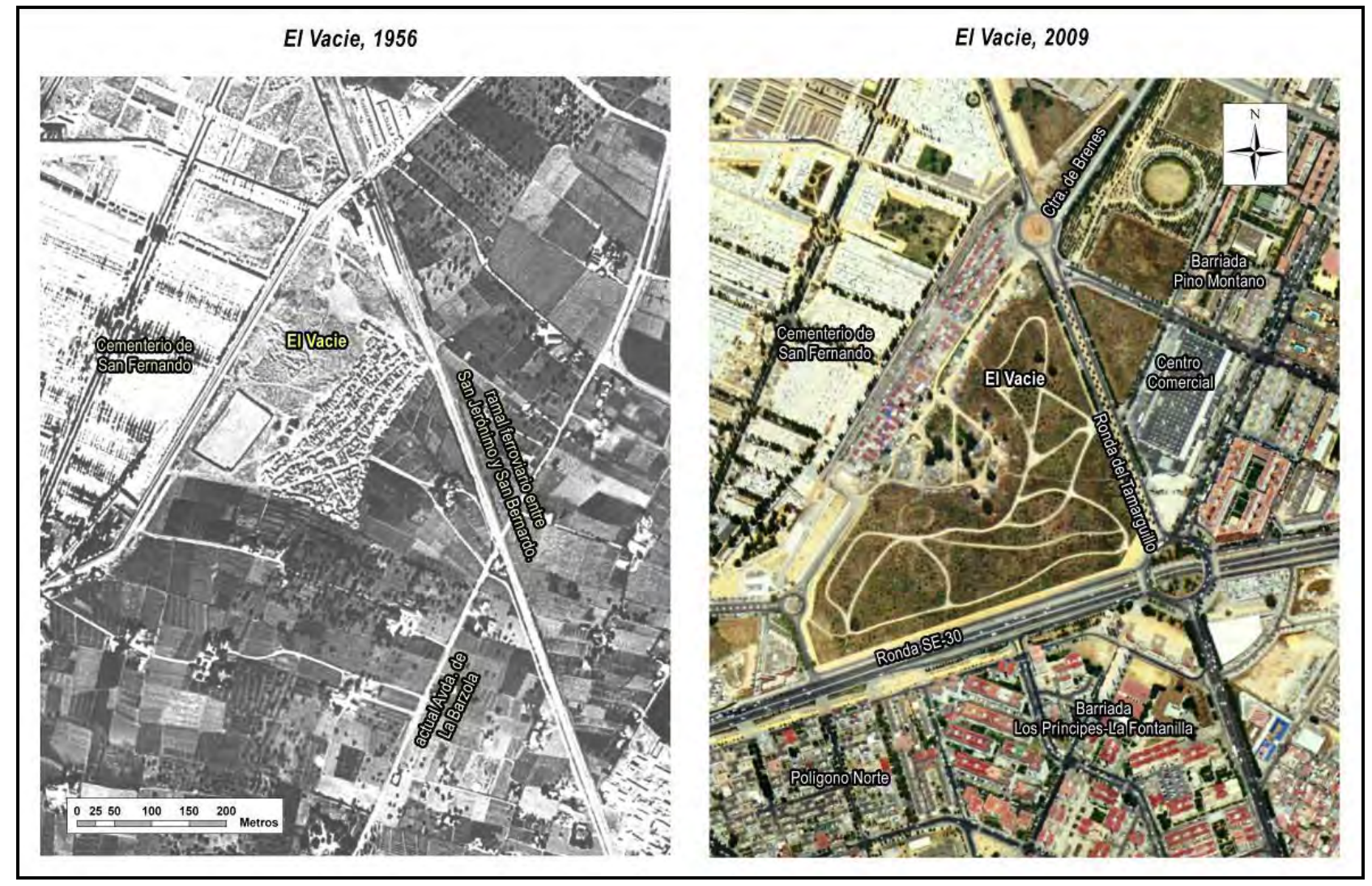

Figura 2. Dimensión histórica y emplazamiento urbano del asentamiento chabolista del Vacie (1956-2009). Elaboración propia a partir de las siguientes fuentes: EI Vacie 1956. Imagen digitalizada de la fotografía aérea de 1956 (vuelo "americano"). Disponible en el Centro de Estudios de Paisaje. Consejería de Gobernación, J.A. El Vacie 2009. Ortofotografía digital en color de Andalucía, 1:10.000 (2004). Junta de Andalucía, Consejería de Obras Públicas y Transportes. Sevilla, $2^{\mathrm{a}}$ ed.

Antes de la etapa constructiva desarrollista (años 60 y 70) el emplazamiento constituye un espacio muy periférico, próximo al Cementerio de San Fernando y apoyándose en la red de caminos que entonces delimitaban las huertas de la zona de Macarena. Según un recuento de chozas de 1959, El Vacie contaba entonces con 900 unidades habitacionales, donde se instalaban 4.214 personas distribuidas en 918 familias, un enorme nivel de hacinamiento que se producía en el que, ya entonces, era el mayor núcleo de estas carac- terísticas en la ciudad ${ }^{2}$.

En la actualidad, y a pesar de que el crecimiento urbanístico de la ciudad ha colmatado todo este sector periférico (nuevos conjuntos residenciales, vías de comunicación, equipamientos comerciales...) estos terrenos mantienen algunos rasgos que lo hacen apartado, residual y que lo devalúan a nivel urbanístico y residencial. Estos rasgos son la proximidad al cementerio, la barrera que consti-

\footnotetext{
2 Datos recogidos en González Dorado (2001), concretamente en su Anexo de Planos, Mapas y Gráficos, Plano n. 34: "Situación de la vivienda, año 1959".
} 
tuye la ronda de circunvalación SE-30 y la propia simbología o connotación marginal que, con el tiempo, ha ido forjándose en torno a este espacio. La permanencia del poblado la interpretamos de este modo en función del mantenimiento de un complejo equilibrio entre las posibilidades reportadas por la asimilación urbana, hecho que facilita contactos sociales y económicos con los barrios circundantes así como el acceso a servicios sociales, la escolarización de los menores, etc., y el relativo aislamiento al que contribuyen los factores ya señalados; éstos son remarcados además por la posición exacta de las chabolas y módulos, alejados de la ronda de circunvalación (el poblado ha terminado prácticamente pegado a la tapia del cementerio), y la cierta ocultación que generan los árboles que delimitan el solar en que se localiza.

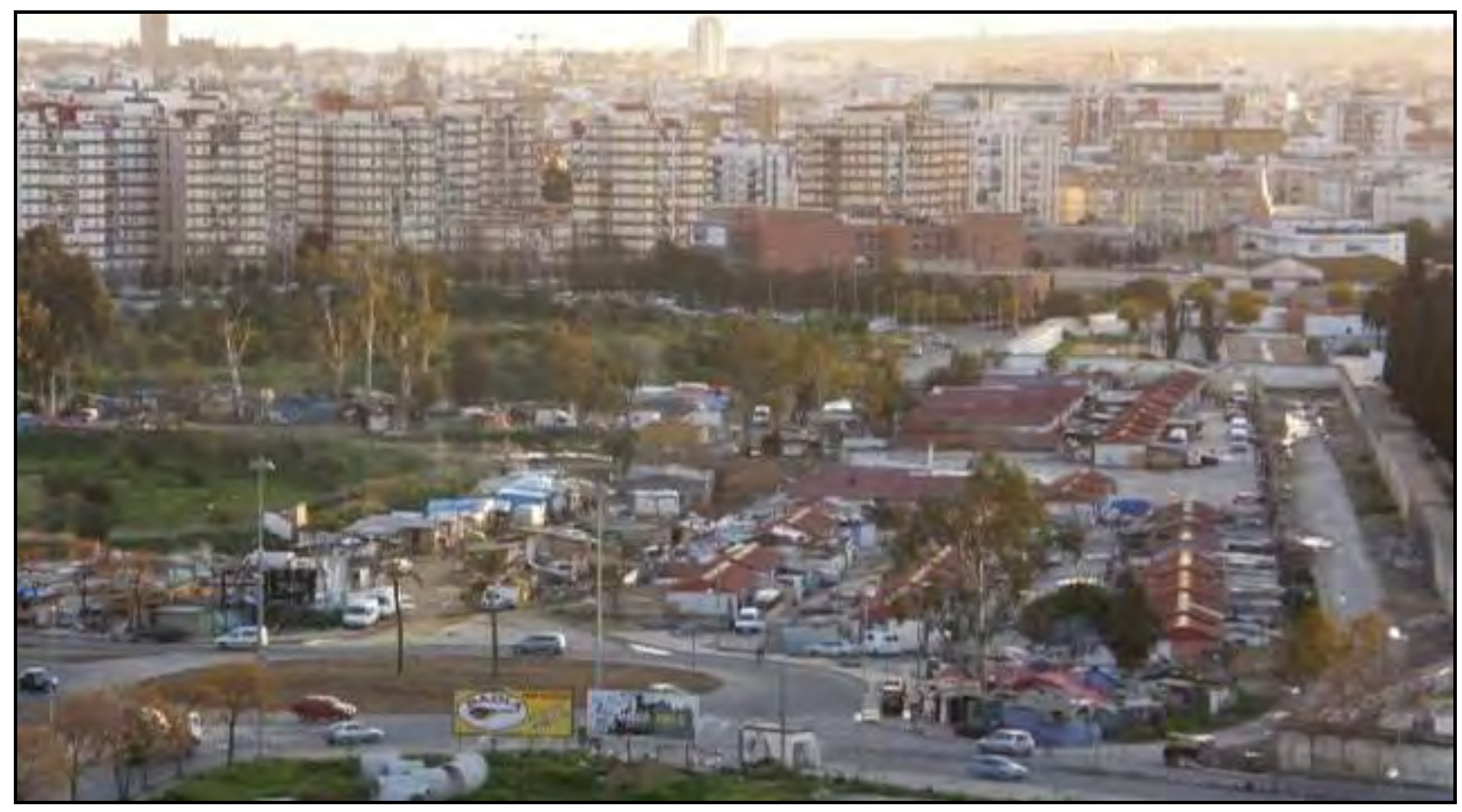

Foto 1. Perspectiva área del Vacie que lo contextualiza en relación al sector norte de la ciudad y el centro histórico. Autor: Antonio López Gándara.

\section{Estructura espacial y composición social}

Entrando en algunos detalles de su situación concreta y de su morfología, el núcleo presenta una estructura lineal de dirección SW-NE, que se encuentra ajustada al límite del cementerio, del que lo separa una calle estrecha. Tiene un acceso principal en su extremo noreste, junto a una rotonda en la que convergen la ronda del Tamarguillo y la carretera de Brenes, y un acceso secundario que se abre en su extremo opuesto o parte trasera; en cuyo lado, una calle comunica directamente con las inmediaciones del Tanatorio de San Fernando y la ronda SE-30.

Su estructura espacial interior está definida a partir de una serie de casitas prefabricadas (aquéllas que se instalaron en torno a 1992) que se alinean a partir de dos calles, siendo una de ellas la que funciona como eje principal. Estas casitas, que acogen a la mayor parte de las familias asentadas, suelen tener algunas ampliaciones gracias a pequeños muros y materiales de desecho; con ellos se crean nuevas habitaciones o se generan espacios delanteros a la manera de terraza, o traseros convertidos en corrales.

Además de estas casitas, el asentamiento cuenta con dos o tres conjuntos o grupos de chabolas, que aparecen algo despegados de la zona principal, mostrando una organización espacial relativamente independiente. Estas chabolas están 
construidas básicamente con materiales de desecho (chapa, madera, cartón...) y muros de fábrica en algunos casos. Uno de los grupos, concretamente el que se encuentra al sur del asentamiento principal, presenta una distribución algo anárquica y sus chabolas se dispersan en torno a senderos y algunos árboles que se levantan en la zona.

Según datos ofrecidos por distintas fuentes, algunas de ellas indirectas -como la prensa-, la población ha ido incrementándose paulatinamente a lo largo de la primera década de este siglo. Un Informe Especial del Defensor del Pueblo Andaluz $^{3}$ habla de 735 habitantes en agosto de 2004. Esta población, fundamentalmente compuesta por personas de etnia gitana, se repartía en 163 familias y contaba con 209 menores de 3 a 16 años. Tanto este informe como el estudio elaborado un año después por la Asociación de Estudios Sociales por la Igualdad de la Mujer (Izquierdo, 2006), confirman que esta población iba en aumento desde hacía algunos años. Por otra parte, el Diario de Sevilla del 24 de noviembre de 2008, en un reportaje dedicado al Vacie, hace referencia a que, de acuerdo con los expedientes de Servicios Sociales, en el poblado viven unas 830 personas repartidas en 225 familias. Un artículo posterior del mismo periódico (Diario de Sevilla, 15/04/2009), contabiliza 908 personas, de las cuales, 225 eran niños. De este modo, ratificamos que el incremento que se observaba a mediados de dicho decenio se ha mantenido constante hasta, prácticamente, el comienzo del actual.

Desde el punto de vista sociológico, parte de la población, concretamente la que se instala mayoritariamente en los módulos de viviendas prefabricadas, se agrupa en un vecindario más o me-

3 Defensor Del Pueblo Andaluz. Chabolismo en Andalucía. Informe Especial. Presentado en el Parlamento de Andalucía el 15-12-2005 y publicado en el BOPA n 377 , de 14-02-2006, VII Legislatura. 258 p. nos estable que muestra algunos rasgos de cohesión y organización comunitaria. Rasgos representados, por ejemplo, en la constitución de un liderazgo de tipo patriarcal que se convierte, a su vez, en interlocutor ante los contactos con agentes externos, como las administraciones, ONG, medios de comunicación, etc. Este hecho ha podido tener cierta relevancia para la articulación de quejas y reclamaciones que se han producido desde los propios chabolistas.

Pero, por otro lado, también se detectan algunas fracturas sociocomunitarias vinculadas a familias que han llegado más tarde y que están compuestas por gitanos de nacionalidad portuguesa; éstos se ubican preferentemente en las chabolas dispersas que se encuentran algo apartadas de la parte principal del poblado. Según informaciones recogidas en 2005 por parte del informe del Defensor del Pueblo Andaluz antes aludido, en aquella fecha existían cinco clanes en el asentamiento: dos portugueses, uno extremeño y dos formados por población radicada en la ciudad.

\section{Hábitat marginal y exclusión social. Una potente dialéctica socio-espacial}

En relación con las condiciones de habitabilidad y las situaciones de exclusión social, los mencionados informes del Defensor del Pueblo y de la Asociación de Estudios Sociales por la Igualdad de la Mujer (Izquierdo, 2006), coinciden en valorar la extrema degradación del asentamiento y las graves problemáticas sociales que se viven en él. Ambos análisis comparten además la idea de que existe una tendencia general hacia el agravamiento de la situación, aspecto que relacionan con el continuo crecimiento del poblado desde comienzos del presente siglo.

Desde el punto de vista físico sus respectivos análisis destacan el pésimo estado de las construcciones, tanto de las viviendas prefabricadas como de las chabolas, y de los suelos no ocupados por ellas, donde resulta deplorable el sanea- 
miento, el suministro eléctrico, etc. Tal como se asevera en Izquierdo: "La basura configura el paisaje y el espacio de juego común para los niños" (ob cit., p. 138).

El analfabetismo generalizado, los problemas de escolarización y el absentismo de los menores, especialmente agravado en el caso de las niñas (que suelen abandonar prematuramente la educación), son, junto a las dificultades de formación e inserción laboral, algunas de las grandes desventajas que acusan estas familias y que no permite romper los círculos viciosos de la exclusión. A ellas hay que sumar otros problemas como las deficiencias higiénico-sanitarias, los riesgos ante determinadas epidemias y enfermedades, la venta y consumo de droga, la violencia ambiental (conflictos vecinales), la delincuencia... y todo ello unido al estigma por ser gitano/a, por ser chabolista y por ser del Vacie.

Algunas de las apreciaciones contenidas en estos informes, obtenidas de las ONG que trabajan en el asentamiento (como la ONG Movimiento por la Paz, el Desarme y la Libertad-MPDL o la ONG Aliento), de técnicos municipales y representantes de instituciones públicas o de los propios vecinos, insisten en las limitaciones que presentan todas las medidas que se ponen en marcha por cuanto no permiten una tutela efectiva de los menores ni un acompañamiento o seguimiento social continuado de éstos y sus familias... En el momento que se interrumpen los programas formativos, en los instantes en que la Guardería deja de funcionar, cuando llega el verano y finalizan las clases escolares, o en tiempo diario, cuando llega la noche y las ONG salen del barrio, la vida del Vacie parece engullir todo lo aprendido, vuelve a ensuciar todo lo que fue limpiado, vuelve a utilizar las herramientas con las que construye su propia miseria ${ }^{4}$.

De acuerdo con este planteamiento, puede hablarse de una potente dialéctica socio-espacial según la cual, las condiciones de vida de estas familias aparecen relacionadas con hábitos de comportamiento que son difícilmente corregibles si no se desvinculan del entorno físico chabolista en el que se desarrollan. Este es un argumento crucial -muy compartido- que plantea la necesidad de la erradicación definitiva de este tipo de hábitat y la ejecución de los consiguientes realojamientos (ordenados, dispersos, particularizados, acompañados) como actuaciones indispensables para la integración social de estas familias. María Jesús Lago, junto a otros autores, sostiene la tesis de que la elevación del nivel residencial implica un mayor grado de integración laboral y, a su vez, un mayor grado de integración laboral rompe el círculo vicioso de la pobreza y evita que los individuos acaben residiendo en chabolas (2004, p. 752). Nos encontramos aquí ante uno de los temas que mayores debates está generando y al que se enfrentan en la actualidad técnicos, asistentes sociales y especialistas. Se trataría de delimitar hasta qué punto influye el abandono del hábitat marginal en el proceso de integración social del colectivo ${ }^{5}$.

\section{¿Por fin la erradicación definitiva del Vacie?}

Un diagnóstico sobre la realidad del Vacie efectuado hace algunos años por los técnicos de Bienestar Social del Ayuntamiento, nos permite reconocer los distintos niveles de exclusión que

\footnotetext{
4 En una entrevista realizada al director del CEIP San José Obrero, éste manifestaba: "lo que los alumnos ganan en el colegio, lo pierden cuando vuelven a su barrio, pero de un día para otro" (Defensor Del Pueblo Andaluz, 2005, p. 27).

Planteamientos como el de Lago sostienen que el realojamiento es la base y el comienzo del proceso de incorporación social de los chabolistas, si bien sólo con el traslado a un piso no se consigue la plena integración. Conseguir una vivienda normalizada es el punto de partida imprescind ble que tiene que ser complementado con el desarrollo de actuaciones sociales y asistenciales encaminadas a la superación de los distintos y sucesivos riesgos de exclusión.
} 
aparecen en el poblado y cómo ello, además, reviste de gran complejidad la intervención pública dirigida a la eliminación del asentamiento y al realojamiento de las diferentes familias. Decía en 2008 la entonces delegada municipal de Bienestar Social, Ana Gómez, ante los medios de comunicación: "entre el $30 \%$ y el $40 \%$ de las familias pueden salir del asentamiento con poquito trabajo y cierta rapidez; otro $30 \%$ requiere un trabajo más a fondo y el $30 \%$ restante es el sector más conflictivo, algunas personas están envueltas en asuntos delictivos y no viven de forma permanente en el poblado" (Diario de Sevilla, 24/11/2008) ${ }^{6}$. Ya en aquel momento, medios de comunicación como el referido anteriormente, transmitían el objetivo de las administraciones públicas de afrontar definitivamente esta cuestión y proceder al desmantelamiento ordenado del asentamiento. En principio, se decidió dotar al poblado de algunas mejoras mínimas en infraestructuras y equipamientos que se estimaron esenciales mientras algunas familias permanecieran en él. $Y$ por otro lado se tomó la decisión de evitar que se produjesen nuevos asentamientos en el poblado a medida que tuviera lugar la salida de las personas realojadas.

Aparte de tomar estas medidas iniciales y previsiones, el proceso de erradicación y subsiguientes realojos, se ha pretendido enfocar en función de los siguientes criterios metodológicos elementales: desarrollar la intervención de manera discreta $^{7}$, tratando de encauzar el proceso de forma personalizada (individualizada según las características de cada familia) y evitar el efecto llamada; preparar previamente a las familias a nivel sanita-

\footnotetext{
${ }^{6}$ Reportaje del Diario de Sevilla de 24 de noviembre de 2008: "Hacia el fin del Vacie. La Junta y el Ayuntamiento de Sevilla planifican la erradicación de las chabolas", elaborado por Reyes Rincón.
}

rio, educativo y de empleo; una vez realojadas en las nuevas viviendas, la fórmula será la de establecer un contrato de alquiler y, posteriormente, no descuidar la atención social a los exchabolistas.

Un artículo periodístico más reciente confirmaba el inicio de los realojos en abril de 2009: "El Ayuntamiento ya ha comenzado el realojo de familias del Vacie en distintos puntos de la ciudad para favorecer su integración social y con la meta de erradicar el poblado chabolista más extenso y antiguo en Andalucía. La concejal de Bienestar Social, Emilia Barroso, explicó ayer que 100 familias ya han sido baremadas para iniciar este proceso de realojos que se desarrollará „con cautela" en todas las zonas de la ciudad e incluso fuera de Sevilla para evitar la concentración de esta población y la formación de nuevos guetos..." (Diario de Sevilla, 15/04/2009).

A partir de 2010, las noticias sobre El Vacie hacen referencia al desarrollo de diferentes actuaciones de saneamiento y adecentamiento de su espacio. En 2011, año en que se produce un cambio de gobierno municipal a favor del Partido Popular, las noticias inciden por lo general en estas mismas cuestiones. No hacen mención del plan de realojos que, teóricamente, se está llevando a cabo en paralelo. En los últimos meses se destacan los recortes presupuestarios que están sufriendo los programas de las distintas administraciones que se definen con estos propósitos $^{8}$.

\footnotetext{
7 Precisamente, este carácter discreto de la actuación es el motivo por el que no contamos con fuentes documentales sobre El Vacie en los últimos años. Ello ha propiciado que tomemos la información de los artículos de prensa como la única fuente para conocer la evolución reciente del asentamiento y las acciones institucionales emprendidas.

Véanse las noticias recogidas por este mismo diario (Diario de Sevilla) en sus ediciones de: 27/07/2010, 08/06/2011, 08/07/2011 y 16/09/2011.
} 


\section{El poblado de Torreblanca y otros asentamientos de menor entidad}

\section{Poblado de Torreblanca}

En la actualidad, aparte del Vacie, el poblado sevillano de chabolas con mayor tamaño se encuentra muy próximo al barrio de Torreblanca, justamente en la margen de la carretera A-8026, que parte desde la autovía de Andalucía (A-92) y toma dirección hacia Mairena del Alcor. Realmente, este asentamiento se encuentra localizado en Alcalá de Guadaíra, aunque pegado a su límite municipal con Sevilla. Tal ubicación fronteriza no nos parece inocua respecto a la consolidación del mismo en este espacio; con ella se ponen de relieve algunas claves específicas que explican la formación y permanencia de este poblado chabolista; aspectos de interés a la hora de enfocar su diagnóstico y su eliminación o transformación.

Aunque hay distintas versiones sobre el origen del emplazamiento de este núcleo, existe cierta coincidencia en que, en realidad, era un asentamiento instalado en la zona de Torreblanca, en el término municipal de Sevilla, próximo al límite con el de Alcalá de Guadaíra. Lo que sucede es que con motivo de unas inundaciones, se trasladó unos metros del lugar, pasando a localizarse en terrenos de este segundo municipio. Ello ha servido para justificar que el Ayuntamiento hispalense se desentienda del mismo y que el alcalareño no termine de ejercer su responsabilidad ante el problema sobrevenido.

El asentamiento, que tiene su acceso desde la carretera mencionada, se ajusta a un camino que sirve primero de prolongación a la calle Inmaculada Concepción (con una dirección SW-NE) y se ciñe posteriormente al eje que conforma la cañada de Pero Mingo (con una dirección predominante W-E). La mayor parte de las chabolas se ubican junto a este camino, extendiéndose a lo largo de más de un kilómetro. Otras se emplazan más próximas a la carretera A-8026 o se disponen junto a los pequeños senderos que se ramifican por el interior de terrenos baldíos, los cuales están comprendidos en un espacio con forma de cuña flanqueado por suelos industriales.

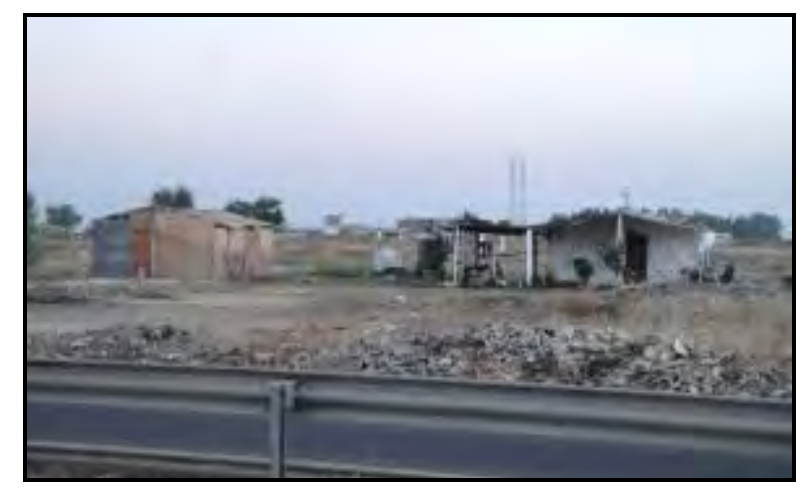

Foto 2. Imagen de algunas de las construcciones dispersas de este poblado próximo a Torreblanca. Elaboración propia.

En cuanto a su población, el censo elaborado en 2005 por el Ayuntamiento de Alcalá, registraba 243 personas y 63 chabolas; este tamaño lo convierte en el segundo asentamiento chabolista mayor de la provincia de Sevilla (tras el Vacie) y el tercero de Andalucía ${ }^{9}$ (Defensor del Pueblo Andaluz, 2005). Un estudio posterior, elaborado a finales de 2008 por uno de los equipos de trabajo participantes en el Máster sobre Gestión Social del Hábitat (1 ${ }^{\text {a }}$. Edición, Curso 2007/2009) ${ }^{10}$, hace referencia a una población aproximada de 300 personas distribuidas en 50 familias.

Este mismo estudio realiza un diagnóstico territorial del asentamiento en el que se muestra una notable degradación física de su hábitat. La carencia de infraestructuras y servicios básicos se ve agravada por la distancia y el aislamiento, físico y social, de las áreas urbanas más cercanas. Junto al creciente deterioro ambiental, cuyas

\footnotetext{
${ }^{9}$ En la fecha del informe, el asentamiento chabolista de mayor tamaño en Andalucía era el de Los Asperones (Málaga) con unas 850 personas distribuidas en sus distintas fases de viviendas provisionales.

10 Máster adscrito a la Universidad de Sevilla (www.master.us.es/geshabitat). El trabajo realizado en este contexto fue el denominado: "Hacia la visibilización de los barrios vulnerables de Alcalá de Guadaíra", elaborado por un equipo conformado por los siguientes alumnos/as: Lidia Berdonces, Luciane Mendes, Leticia Pérez, Marta Solanas y Ramón Teruel.
} 
consecuencias se reflejan en la aparición de enfermedades como hepatitis B y tuberculosis, se hace referencia a unos altos niveles de conflictividad, los cuales se deben en parte a las actividades ilícitas que se realizan, entre ellas la venta de drogas.

Por otro lado, la sociabilidad se muestra, probablemente, aún más mermada que en el asentamiento del Vacie. La alta dispersión de los grupos de chabolas guarda relación con una fragmentación social que, a su vez, adquiere ciertos rasgos de estratificación: por un lado, se diferencian familias de gitanos españoles, de otras compuestas por gitanos portugueses y otras de gitanos rumanos; este diverso origen nacional se conjuga, más o menos coincidiendo con este orden, con el tiempo de permanencia en el poblado, imponiéndose los que tienen mayor arraigo a los que han llegado posteriormente. Asimismo, los distintos informes corroboran una alta movilidad en el asentamiento, es decir, con cierta frecuencia se desmantelan chabolas y se crean otras nuevas. Esta inestabilidad significa una mayor precariedad y conflictividad.

Los chabolistas vinculan sus actividades cotidianas al ámbito urbano más próximo (barrio de Torreblanca) pero, sin embargo, deben recibir atención desde los Servicios Sociales Comunitarios de Alcalá de Guadaíra, ayuntamiento que además tiene la responsabilidad de una posible intervención transformadora sobre este espacio.

En la actualidad, la situación de este poblado no ha cambiado significativamente; es decir, no existen expectativas fundadas de un proyecto de erradicación del poblado que prevea el realojamiento de sus habitantes. Contemplando la posibilidad de que se lleve a cabo, la singularidad "intermunicipal" de este núcleo requiere de un diagnóstico que analice, entre otros aspectos, las interacciones o contactos que se producen con poblaciones, lugares y actividades del entorno (Torreblanca, pedanía alcalareña de San Rafael, polígonos industriales...), las fragmentaciones y estratificaciones observadas, los niveles de movilidad que se detectan y las posibilidades de integración que, en función del grado de vulnerabilidad/exclusión que acusan, ofrecen cada una de las familias.

Tomando como base tal diagnóstico, la intervención debería ser coordinada y ejecutada bajo una concepción metropolitana del fenómeno, implicando a los dos ayuntamientos afectados. El alcance metropolitano que hoy tienen muchas de las expresiones territoriales de la vulnerabilidad social y la exclusión, incluida el chabolismo, deberían tener un tratamiento también dimensionado a esta escala, en la que aún no existe una autoridad o comisión competente que pueda afrontar estas complejas problemáticas compartidas.

Aparte de los dos asentamientos principales analizados (El Vacie y el poblado de Torreblanca), existen en Sevilla otros núcleos de menor importancia por sus dimensiones físicas y demográficas y que, en principio, responden a emplazamientos más inestables o transitorios. Entre estos casos, a pesar de constituir un número reducido, nos encontramos con una notable heterogeneidad según su grado de consolidación y arraigo, su morfología y, en algunos ejemplos excepcionales que veremos, cambia incluso el destino de su construcción. Describimos brevemente algunas características de estos asentamientos de menor entidad.

\section{Viviendas prefabricadas de la Avenida de La Paz}

Junto a la Avenida de La Paz y la barriada de Las Letanías aún se levantan 20 casitas prefabricadas; éstas fueron instaladas en pleno Polígono Sur a principios de la década de los noventa del pasado siglo. Como ocurre con numerosos casos similares mayormente característicos en décadas pasadas (como las Unidades Vecinales de Ab- 
sorción de los años 60 y 70), fueron construidas para realojar de manera transitoria hasta encontrar alojamientos más dignos, a algunas familias que habitaban en chabolas en las inmediaciones de la misma avenida.

Curiosamente, una de las dificultades que han encontrado asentamientos como éste para su erradicación, ha sido la propia definición de "núcleo chabolista" que establecía el Plan Integral de Erradicación del Chabolismo. Según el texto del Defensor del Pueblo Andaluz en su Informe al Parlamento de 2001, la Consejería de Obras Públicas y Transportes de la Junta de Andalucía (ámbito político-administrativo al que se adscribe el Plan) no consideraba "chabolas" este tipo de viviendas, a pesar de que, en muchos casos, y éste de La Paz es uno representativo, el estado de aquéllas ha empeorado con el tiempo llegando a convertirse claramente en infraviviendas. Según actuaciones emprendidas con posterioridad en otros asentamientos (el de La Paz-Las Letanías sigue vigente), este criterio de la administración autonómica parece haberse corregido.

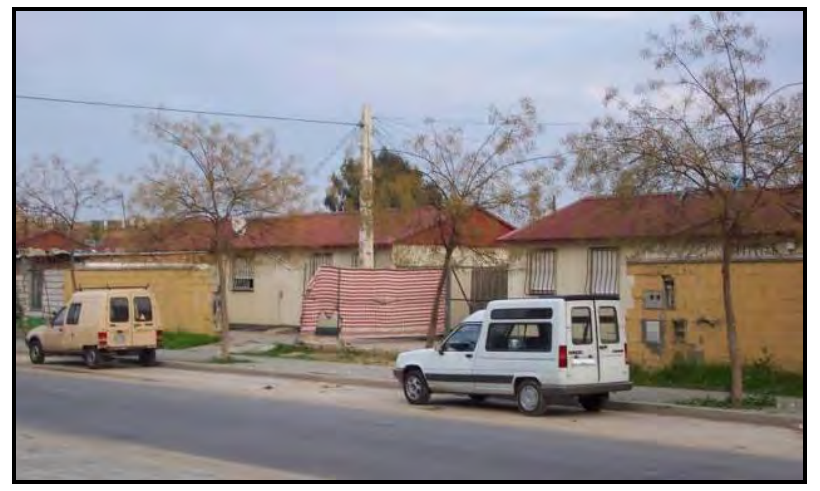

Foto 3. Viviendas prefabricadas en Polígono Sur (año 2002). Actualmente sólo quedan unos pocos módulos junto al ya construido Centro de Servicios Sociales. Elaboración propia.

\section{Chabolas junto al canal de Ranillas}

Se trata de un asentamiento que también aparece reflejado en el Informe Especial del Defensor del Pueblo (2005), aunque de forma muy escueta y restándosele importancia al llevar pocos años construido en el momento en que se realizó el
Informe (a aquellos años hay que sumarles, por tanto, los transcurridos hasta la actualidad) y estar ocupado por sólo cinco o seis familias. De este núcleo habría que resaltar, sobre todo, las difíciles condiciones de su emplazamiento: se sitúa en el borde de un canal de riego (el de Ranillas) y con muy poco espacio entre la fuerte pendiente de su margen, donde aparecen algunos vertidos incontrolados, como escombros y basuras, y el murete y vallado que separa de las naves donde se localizan los servicios centrales de la empresa estatal Correos.

Las condiciones de infravivienda, inseguridad e insalubridad de este peculiar enclave chabolista fueron denunciadas en el Manifiesto "Por la SeviIla Invisible", texto elaborado por la Delegación en Sevilla de la Asociación Pro-Derechos Humanos de Andalucía, y proclamado en una jornada reivindicativa efectuada en 2009. En ella se realizó un recorrido a lo largo de algunos barrios y asentamientos que, como éste, formarían parte de la Sevilla marginada y por ello "invisible". La participación en aquella jornada me permitió conocer el lugar en el que se emplaza este asentamiento. La impresión generada por el mismo queda descrita brevemente en las siguientes líneas:

"...La parada la hicimos en la ronda de Ranillas, en el punto en el que ésta cruza por encima del canal que recibe ese nombre. La razón era poder visualizar desde allí el pequeño grupo de chabolas, alrededor de una decena de chozas y cobertizos, instalados desde hace algunos años en los bordes del conducto. Concretamente, se emplazaban sobre uno de los márgenes sobreelevados que delimitan el canal, pegado al murete que separa de las instalaciones de Correos y exponiéndose abiertamente sobre la vaguada artificial, ante una pendiente cubierta de todo tipo desechos que se desparramaban hacia el fondo. Hasta las chabolas llega un caminito que parte 
desde la ronda. Resulta sorprendente cómo aquella destartalada composición de chapas, maderas y cartones, en un entorno semejante al de algunos núcleos chabolistas del Tercer Mundo, encontraba su refugio en un espacio de esas características, guardando un equilibrio imposible sobre muy pocos metros de tierra firme, entre la pared y esa infesta pendiente que podía convertir un despiste o mal paso en una desgracia. Entendí entonces que aquella segunda parada en el recorrido también estaba justificada por las condiciones de vida que se escondían en ese insólito lugar. En este caso, los derechos humanos socavados afectaban muy especialmente a la necesidad de vivienda que tienen esas personas y a la dignidad que deben tener los alojamientos en los que vivan" (Torres, 2009).

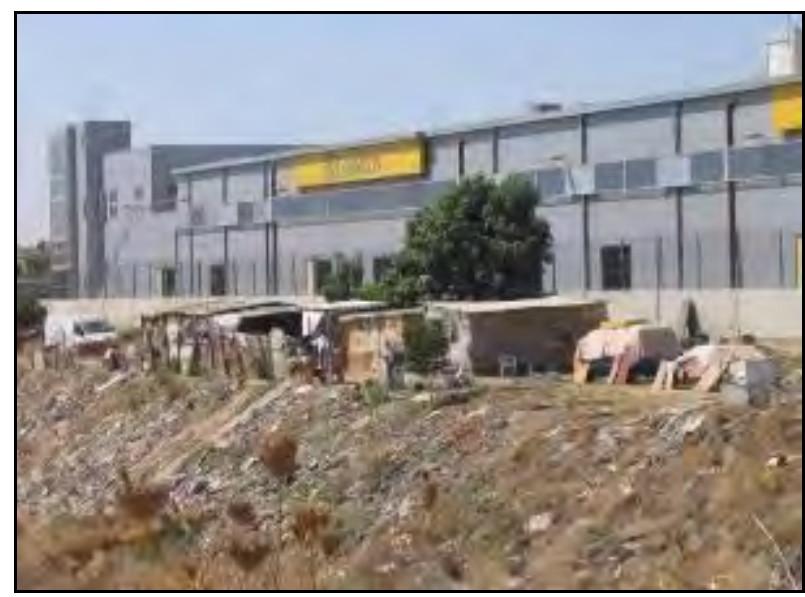

Foto 4. Chabolas junto al canal de Ranillas. Autor: Francisco Javier Gutiérrez Núñez.

\section{Tablada, Charco de la Pava y los puentes hacia el Aljarafe: San Juan o "Puente de Hierro"}

Los terrenos de Tablada, Charco de la Pava o Vega de Triana, situados junto al Guadalquivir, donde varios puentes lo cruzan hacia el Aljarafe, se han convertido en unos espacios aparentemente propicios para acoger asentamientos muy precarios o provisionales de este tipo. Los bajos de los puentes (puente de San Juan, Juan Carlos I o Reina Sofía) se convierten en "refugios" temporales para grupos, familias o personas que viven en graves condiciones de pobreza o vulnerabilidad social. Son habitantes que pueden provenir de antiguos asentamientos de la ciudad o, cada vez con más asiduidad, son inmigrantes, en su mayoría de Europa del Este, como los gitanos rumanos, que se instalan en estos lugares con el fin de trabajar temporalmente en Sevilla.

En estos espacios aparecen nuevamente dos rasgos territoriales que adquieren un singular valor en estos contextos de exclusión: son lugares muy próximos a las áreas urbanas (estos espacios referidos tienen, incluso, un emplazamiento geográfico intermedio en relación con el área metropolitana) donde se puede acceder a agua potable y a otros recursos; al mismo tiempo, ofrecen una localización relativamente marginal y apartada... son suelos inundables, muy poco frecuentados y escasamente visibles. A esto último se añade, además, una cuestión que no parece nada baladí: pueden ser enclaves muy próximos a los límites municipales o que los "pisan" prácticamente, aspecto que suele jugar a favor de su "invisibilidad institucional" al generar dudas acerca de las responsabilidades que recaen en los ayuntamientos implicados. La asunción de responsabilidades puede resultar aún más diluida cuando los suelos pertenecen a determinados organismos públicos de distinto carácter, como pueden ser los ministerios estatales, la Confederación Hidrográfica, la Autoridad Portuaria, etc.

En concreto, el puente basculante de San Juan de Aznalfarache, también conocido como "Puente de Hierro", constituye un espacio frecuentemente elegido como una de las primeras o mejores alternativas posibles para la implantación chabolista. En 2005, las inspecciones realizadas identificaban varios grupos de asentamientos independientes entre sí: un asentamiento de algo más de diez chabolas ocupadas por familias rumanas; una o dos chabolas pertenecientes a una familia 
gitana procedente de Villanueva del Río y Minas y varias roulottes donde vivían familias procedentes de Almendralejo (Badajoz) y Ciudad Real. Las diferentes personas allí consultadas justificaban de manera distinta su asentamiento en aquel lugar.

Por otra parte, desde hace algunos años, el problema del chabolismo en Sevilla se ha diversificado a partir de la llegada de familias gitanas de origen rumano. Algunas de estas familias se instalan en campamentos muy precarios, con tiendas de campaña que reúnen junto a sus vehículos, construyendo pequeños asentamientos que suelen ser desmantelados por la policía en poco tiempo. Esta nueva vertiente del fenómeno chabolista, en la que se acumulan tres graves factores de vulnerabilidad y exclusión (inmigración, etnia gitana, chabolismo) representa un importante reto en relación al enfoque y tratamiento que debe recibir por parte de las administraciones, hasta ahora centradas en una labor fundamentalmente policial.

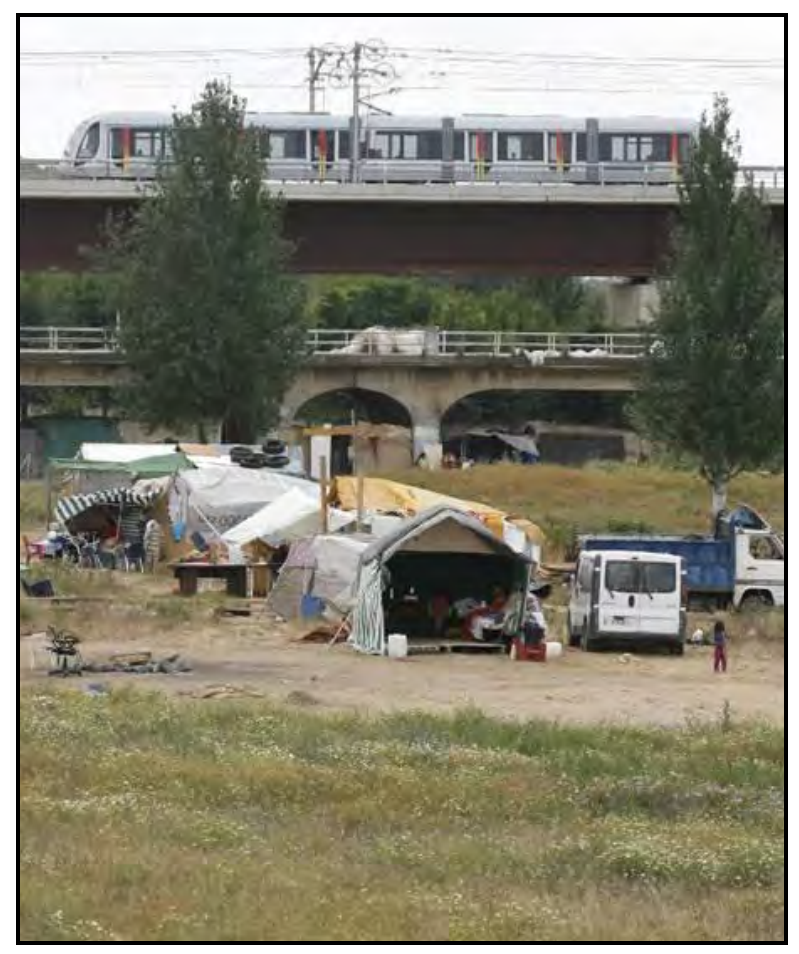

Foto 5. Chabolas junto al puente de San Juan. Autor: Javier Barbancho. Diario EL PAís-Andalucía (12 de mayo de 2009). Archivo de ELPAIS.com

\section{Cobertizos y caballerizas entre Padre Pío (Palmete) y el Guadaíra}

Otros casos muy singulares que también incluimos en esta relación de asentamientos chabolistas secundarios, están representados por núcleos en los que, si bien puede existir alguna chabola o caseta destinada a un uso habitacional, se componen fundamentalmente de caballerizas, cobertizos y otras estructuras muy precarias no vinculadas con el alojamiento sino con actividades muy residuales de tipo agroganadero, productivo o de almacenaje.

Dos ejemplos de este tipo aparecen recogidos en los documentos del nuevo Plan General (PGOU de 2006) ${ }^{11}$ con la catalogación de "núcleos de chabolas". Ambos están situados próximos a los barrios de Palmete, en el borde ESE de la ciudad, en unos terrenos emplazados entre la ronda SE30 y su variante de conexión con la A-92 y el cauce del río Guadaíra. Se trata de un ámbito territorial muy desordenado, compartimentado por infraestructuras muy diferentes y con diversos usos entremezclados, todos ellos con una apariencia muy informal. Probablemente, estos núcleos apoyen su subsistencia en estas condiciones de desorden y marginalidad urbanística, aspectos a los que se suma, nuevamente, el hecho de ubicarse, justamente, en el límite muncipal entre Sevilla y Alcalá de Guadaíra.

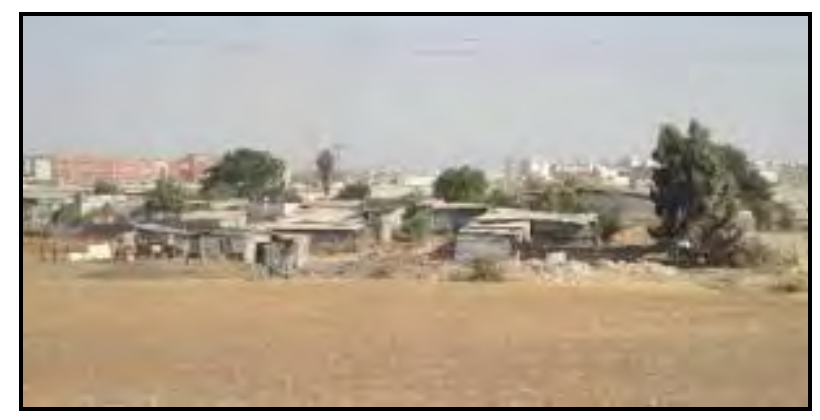

Foto 6. Perspectiva del asentamiento desde los terrenos de la Universidad Pablo de Olavide. Elaboración propia.

11 Oficina del Plan de Sevilla. Estrategias para la cohesión urbana. Documento de oportunidades y estrategias para la ordenación urbana-territorial de Sevilla. En Nuevo Plan General Municipal de Ordenación. Oficina del Plan de Sevilla, Ayuntamiento de Sevilla, 2006. 


\section{Desiguales experiencias en los procesos de erradicación y realojo}

Aparte de ofrecer estas breves descripciones y caracterizar los pequeños núcleos de chabolas que se levantan de forma puntual e intermitente, queremos hacer hincapié en las formas en que se ha intervenido y procedido a la erradicación de algunos de los asentamientos chabolistas que existían en Sevilla hasta hace pocos años. Las intervenciones dirigidas expresamente a la erradicación del chabolismo en la ciudad fueron impulsadas especialmente a partir de 1997, fecha en que fue aprobado el Plan Integral de Erradicación del Chabolismo en Andalucía (Consejo de Gobierno del 25 de noviembre de 1997, Junta de Andalucía) $^{12}$.

Entre sus determinaciones normativas, se establecían una serie de objetivos generales a los que debían responder las iniciativas correspondientes. Éstos, además de proponer la erradicación de este problema mediante el diseño y ejecución de una vivienda adecuada, acompañada del equipamiento comunitario primario y las infraestructuras urbanas necesarias, incluían otros requisitos como la promoción laboral de los habitantes de los núcleos chabolistas, la atención a la Salud Pública con acciones individuales y colectivas, actuaciones de índole educativa, como la plena escolarización de niños y niñas, la reducción del absentismo, el fomento de la educación de adultos, así como acciones sociales encaminadas, en general, a la mejora de las condiciones sociales de las familias.

Sin embargo, las inercias y presiones de un urba-

\footnotetext{
${ }^{12}$ Acuerdo de la Consejería de Presidencia, de 25 de noviembre de 1997, por el que se aprueba el Plan Integral para la Erradicación del Chabolismo en Andalucía (BOJA núm. 52, de 9 de Mayo de 1998). Las propuestas de actuación recogidas en el Plan fueron diseñadas tomando como base el Inventario Cualificado de Núcleos Chabolistas de Andalucía, elaborado por la Dirección General de Arquitectura y Vivienda, que detectaba un total de 580 chabolas en el territorio andaluz, de las cuales 225 estaban agrupadas en siete grandes núcleos chabolistas y 355 agrupadas en pequeños núcleos o de localizaciones dispersas.
}

nismo especulativo, tendente a la segregación, el posicionamiento de vecindarios o entidades vecinales guiadas por prejuicios -cuando no por actitudes manifiestamente racistas y xenófobasy la actitud de una administración municipal que, sin atender a unos mínimos principios y criterios de responsabilidad política, trata de acomodar su acción a los intereses de unos y otros, ha significado la consecución de actuaciones aceleradas, muy efectivas económicamente, la financiación que se destina al desmantelamiento libera los terrenos ocupados para su posterior urbanización..., pero muy negativa socialmente, no ha existido por lo general un proyecto de realojamiento que conlleve la tutela social de los chabolistas (antes, durante y después del realojo) y que respete los Acuerdos establecidos en la normativa del Plan.

Esta solución meramente gestora, simplista y deshonesta en vez de transformadora, ha supuesto no sólo que algunas situaciones de chabolismo se perpetúen y reproduzcan, sino también ha significado el deterioro de la convivencia en los nuevos entornos sociales donde estas poblaciones han terminado reasentándose y ha contribuido a la estigmatización del chabolista como sujeto que no "sabe vivir ni convivir" en áreas urbanas consolidadas.

La Figura 3 sintetiza los distintos modos o fórmulas con los que se ha practicado la erradicación y se ha inducido el realojamiento desde el año 1997. Los procedimientos para llevar a cabo estas iniciativas han sido muy diferentes, incluso podrían valorarse opuestos en el objetivo esencial que los inspira: mientras que en algunas operaciones la erradicación consigue ser programada en función de una transformación prácticamente in situ, en el mismo entorno urbano y social del poblado, cimentándose así algunas de las bases para una integración social posterior (este fue el modelo seguido en la operación de San Diego 
entre 1997 y 1998), en otros casos, sin embargo, se imponen la eliminación del núcleo y el desplazamiento de su población como acciones prioritarias y casi exclusivas, obviando las medidas que deben apoyar un adecuado proceso de realojamiento. Este segundo procedimiento estaría representado, a grandes rasgos, por las operaciones de Perdigones en 2001 y Bermejales en 2004. Valoramos a continuación dichas iniciativas según las estrategias adoptadas en cada caso y el éxito o fracaso que nos sugieren de acuerdo con los resultados obtenidos.

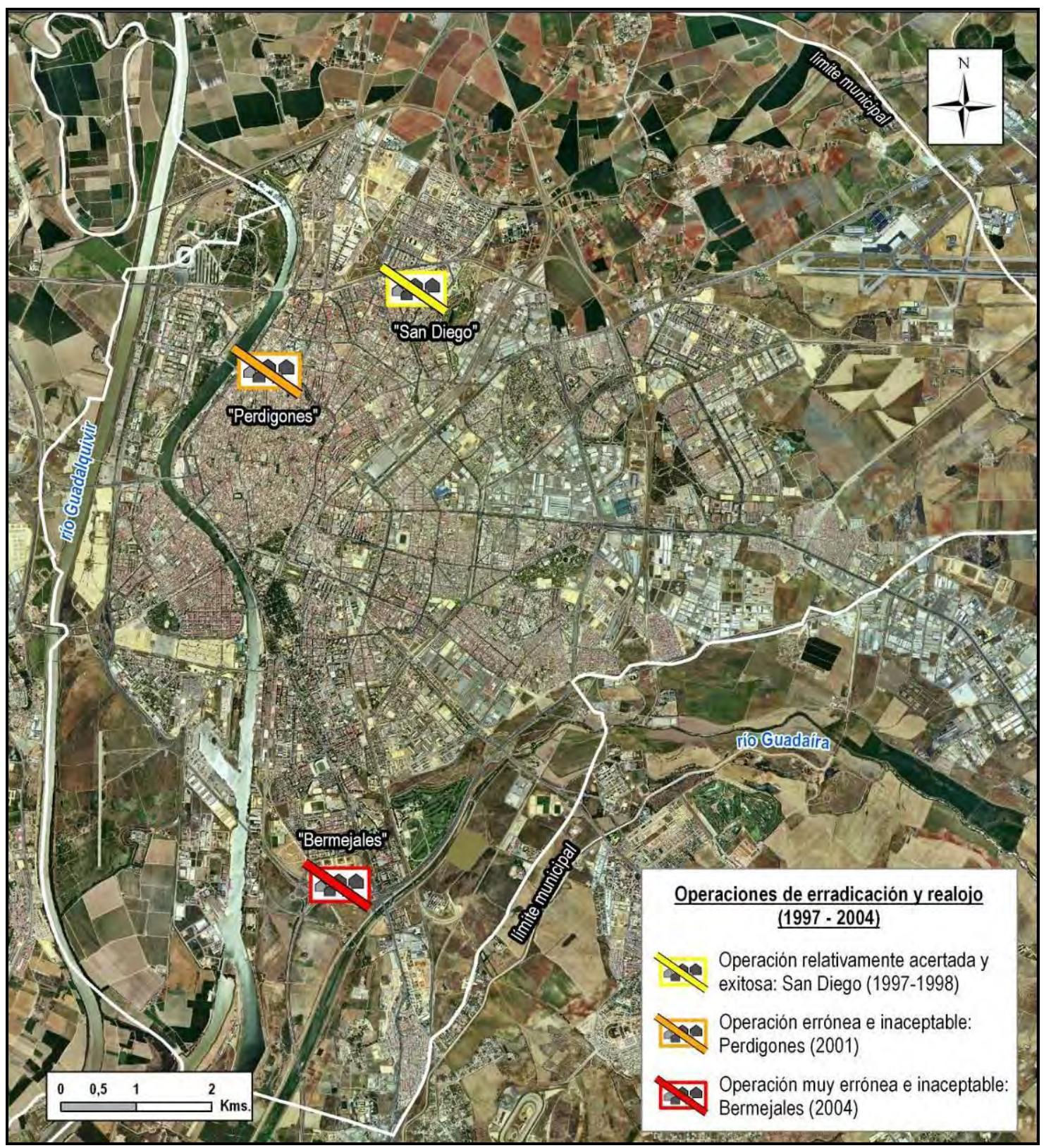

Figura 3. Valoración de las operaciones de erradicación y realojo llevadas a cabo entre 1997 y 2004 . Fuente: Elaboración propia.

\section{El relativo éxito de la iniciativa de San Diego}

La operación de erradicación y realojo de los chabolistas de San Diego consistió, básicamente, en el reasentamiento de las familias en un lugar muy próximo, prácticamente inmediato, al del poblado original, asignándose viviendas unifamiliares de propiedad municipal en régimen de alquiler a cada una de aquellas familias. Las viviendas fueron financiadas por la Junta de Andalucía, que así ponía en marcha el Plan Inte- 
gral de Erradicación del Chabolismo en Sevilla, y promovidas por el ayuntamiento hispalense. La erradicación se produjo mediante un proceso ordenado en varias fases entre 1997 y 1998. A medida que se construían las viviendas, se ponían en marcha, de forma paralela, las distintas fases de desalojo-realojo.

Tal proceso llevado a cabo se había anunciado y preparado con antelación. En gran medida, y en esta dirección creemos que puede entenderse el éxito con el que se valora esta intervención, la operación se había fraguado a partir del fortalecimiento de vínculos entre los vecindarios colindantes (de San Diego y de Los Carteros) y la población del núcleo chabolista, fundamentalmente de etnia gitana.

En este sentido, debió tener gran importancia la labor no sólo formativa, sino también socializadora, de centros como el de Educación de Adultos en Los Carteros-San Diego. El trabajo desarrollado durante más de dos décadas había servido para conocer e integrar a algunas familias gitanas que se asentaban en las chabolas. La experiencia al respecto de la educadora Julia Luza, conocida en una entrevista realizada en 1995, revela la importancia que, más allá de los resultados formativos, pudieron tener estas actividades ${ }^{13}$.

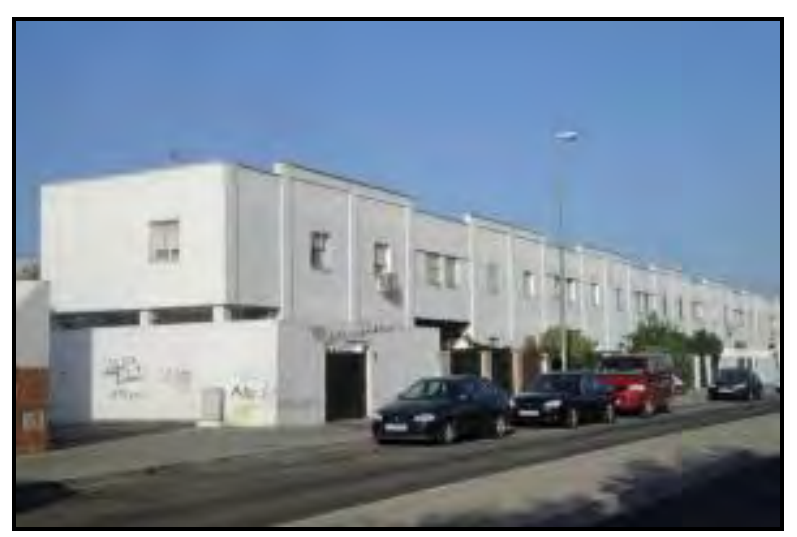

Foto 7. Tipología de viviendas en las que fueron realojadas algunas de las familias gitanas del poblado que existía en el lugar. Calle Baltasar. Elaboración propia.

\footnotetext{
13 Los detalles de esta entrevista pueden leerse en Caraballo (1999, p. 82).
}

Aparte del trabajo en estos centros, así como la participación en algunas fiestas, celebraciones y actividades conjuntas como la del mercadillo semanal, tuvieron gran trascendencia los posicionamientos representados por las entidades vecinales en ciertos momentos claves. Si bien, entre una parte del vecindario, los estereotipos e injustas generalizaciones infundían manifestaciones de rechazo social hacia los chabolistas, en el lado contrario, en el que tuvieron notoria influencia algunos liderazgos vecinales pertenecientes, sobre todo, a la Asociación de Vecinos "Andalucía" de San Diego, aparecía una reacción a favor de aquellos otros, "también vecinos", del otro lado de la carretera de Pino Montano que malvivían en chabolas, apoyando incluso con "contramanifestaciones" el realojamiento de los chabolistas en nuevas viviendas en aquel mismo sitio.

Aunque las posturas defendidas por unos y otros vecinos significaron evidentes controversias y objeciones al proyecto de realojamiento -aspecto éste que matiza el idealismo de aquellas interpretaciones que quieren ver en el caso de San Diego un desarrollo lineal y positivo en todos sus términos-, aquellas "contra-manifestaciones" de vecinos de este barrio y de Los Carteros a favor de la permanencia de los chabolistas en su entorno urbano y social debieron percibirse como una acción totalmente insólita, una acción que, a pesar de algunos problemas de convivencia, deben mostrarse hoy con el orgullo de haberse convertido en un símbolo del diálogo y el encuentro entre diferentes grupos sociales y culturales en la ciudad de Sevilla: todo un "espacio de esperanza" que pone en evidencia otras posturas intolerantes que surgen actualmente entre determinados sectores vecinales. Más detalles de la historia social y política del barrio de San Diego, pueden consultarse en la indicada obra de Rosario Caraballo (1999). 


\section{Perdigones, "dinero y cierto acompañamiento social"}

La valoración que hacemos de este caso es mucho menos positiva. La erradicación del núcleo de Perdigones se llevó a cabo en 2001, veinte años después de su implantación en aquel espacio situado en la calle Resolana y bajo la torre de Perdigones, en el área de La Macarena. Supuso el desalojo de 38 familias de aquellos terrenos para que la constructora Prasa los convirtiese en un núcleo residencial (bloques de viviendas), en un amplio espacio público próximo al río y en una zona verde. Todo ello supuso una inmediata recualificación ambiental de aquel sector de la ronda histórica y de las instalaciones universitarias que lo rodean.

Las familias afectadas por aquella intervención -gravemente simplificadora y consistente, especialmente, en la entrega de unos sobres con seis millones de pesetas-, no fueron por tanto realojadas en el mismo lugar sino que se repartieron por el resto de la ciudad. A la mayor parte de ellas se les facilitó el acceso a una vivienda social, haciéndose efectiva tal operación en muchos casos; sin embargo, a pesar de que en algunos de éstos se tomaron medidas de acompañamiento social, la carencia de criterios a la hora de reubicar a tales familias se convirtió en el principal problema observado en este caso de Perdigones.

Según la información contenida en el Informe Especial elaborado por el Defensor del Pueblo Andaluz (2005), los chabolistas de Perdigones se dispersaron de la siguiente manera: varias de las familias se fueron al Polígono Sur, comprando viviendas no regularizadas; otras se fueron a una urbanización ilegal en Alcalá de Guadaíra; el resto, se desconoce dónde pudieron terminar residiendo.

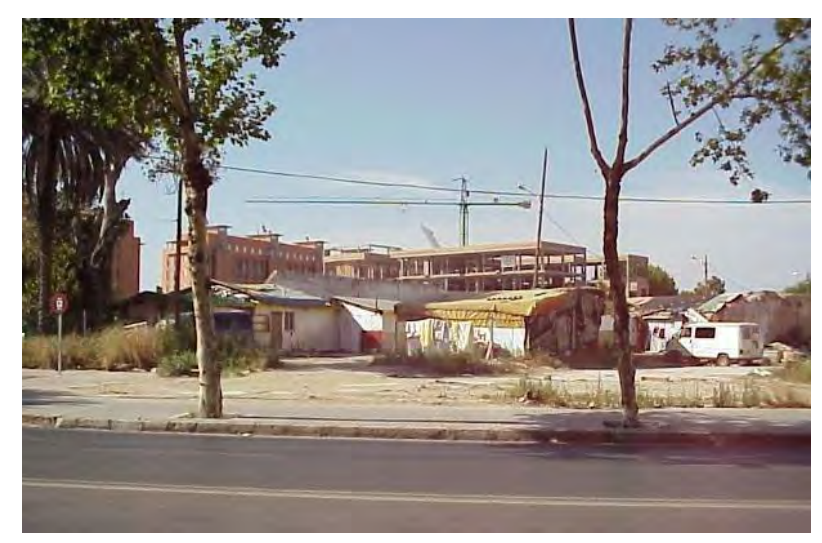

Foto 8. Imagen de las chabolas que existían en el entorno de la torre Perdigones. Autor: Ventura Galera Navarro.

\section{Bermejales, "dinero y nada más”}

En este caso no se puede hablar, en modo alguno, de un plan o modelo de intervención al respecto. La estrategia seguida no fue otra que la de propiciar el desalojo de los terrenos situados al sur de Bermejales mediante la entrega de una cantidad económica a las familias allí asentadas, $42.000 €$ para cada una de las conformadas en aquel momento. Esta operación, que esperaba que tales familias invirtieran tal dinero en conseguir una vivienda, sin ningún tipo de control o regulación sobre cuándo, dónde ni cómo debía realizarse esta compra, consiguió únicamente lo que parecía ser su objetivo primordial: liberar aquellos terrenos de "personas marginales y molestas" y contar con el suelo para destinarlo a la construcción de nuevos bloques de viviendas.

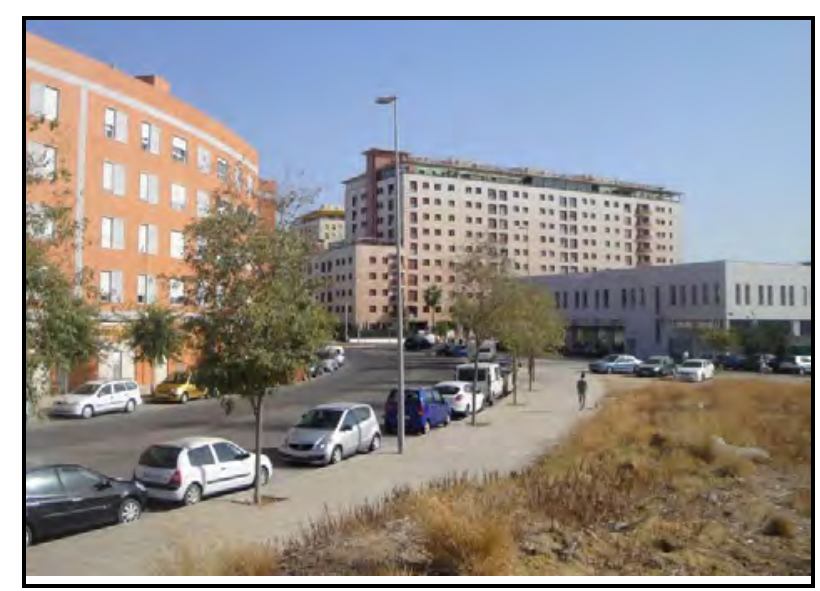

Foto 9. Bloques de viviendas y equipamientos levantados en las inmediaciones del espacio que ocupaba el poblado de Bermejales. Elaboración propia. 
Muchas de aquellas familias terminaron instalándose de forma irregular en viviendas de Polígono Sur, lo que significaría nuevos problemas de convivencia y marginación en barriadas como Murillo o Martínez Montañés, ya de por sí muy desfavorecidas y con un tejido social muy debilitado. Este problema se sumaba así a las difíciles condiciones sociales de barrios como los indicados y a sus delicadas experiencias en materia de convivencia y seguridad. La constitución de una institución política particular, como es el Comisionado para el Polígono Sur, y su interés por poner en marcha un Plan Integral para su transformación y desarrollo, se vieron empañadas por las consecuencias derivadas del desmantelamiento de Bermejales y la posterior arribada de los chabolistas. Aquel fenómeno supuso un verdadero varapalo para las expectativas que se habían puesto en su proyecto.

\section{Bermejales cinco años después, un fenómeno complejo complicado por la falta de compromiso político}

Aquella opción de ofrecer dinero a los chabolistas de Bermejales para que abandonasen el asentamiento, sin la menor garantía de que accediesen a nuevas viviendas de forma regularizada y normalizada, se convirtió, como se ha dicho, en un nuevo y grave problema para los barrios de Polígono Sur, un problema que irrumpía en aquel momento sobre los objetivos transformadores del Comisionado y del Plan Integral que con él se ponía en marcha.

Tras el paso de algunos años, en los que las iniciativas de integración social de aquellos chabolistas han sido infructuosas, el conflicto generado entre distintos clanes gitanos en la primavera del año 2009, provocó que las familias que llegaron de Bermejales, instaladas en viviendas de Murillo que habían comprado irregularmente, tuviesen que abandonar el barrio por miedo a una venganza, volviendo así a recuperar su estado chabolista. Después de salir del barrio y asentarse en la zona de Tablada, en los bajos del puente de San Juan, sufrieron continuas expulsiones y desplazamientos por descampados de los alrededores de la ciudad; cuatro meses después del origen de los acontecimientos y de abandonar Polígono Sur, la ubicación definitiva de estas personas no había podido aún resolverse ${ }^{14}$.

Este desarrollo de los acontecimientos descubre, por un lado, la complejidad inherente a situaciones de exclusión que reúnen, en una misma realidad, las diferencias étnicas y culturales, los hábitos de vida que han sido orientados por la pobreza y la supervivencia marginal, y el carácter material y simbólico (estigmatizado) del chabolismo. Pero también descubre las dificultades políticas por adoptar los mecanismos más adecuados para afrontar la situación, mecanismos que no pueden ser automáticos y que no deberían aprovechar prejuicios y estereotipos populares para justificarse.

No es objeto de este artículo detenerse exhaustivamente en el desarrollo de aquellos acontecimientos. No obstante, queremos subrayar la significativa posición tomada entonces por el Comisionado del Polígono Sur ${ }^{15}$. En un comunicado realizado el 4 de agosto de 2009, esta institución trata de explicar en varios puntos su rechazo a que las familias que tuvieron que huir del barrio volviesen a las casas, ya que, en su mayo-

\footnotetext{
14 El artículo recogido en El PAIS-Andalucía el domingo 9 de agosto de 2009, escrito por Ángeles Lucas, sintetiza perfectamente el modo en que se desarrollaron los acontecimientos desde el mes de marzo, así como los enfoques y posicionamientos adoptados por algunos de los actores y agentes (civiles y políticos) que se vieron implicados con distinto protagonismo y distintas responsabilidades en la cuestión: "Un drama de integración, éxodo y abandono" (EI PAÍS-Andalucía, 09/08/2009).

<http://www.elpais.com/articulo/andalucia/drama/integracion/e xodo/abandono/elpepiespand/20090809elpand_3/Tes>.

15 Institución política de carácter excepcional centrada en la transformación social de Polígono Sur, un área especialmente deprimida de la ciudad. Su papel es el de coordinar las actuaciones de las distintas administraciones públicas en la zona y desarrollar diferentes líneas de intervención enmarcadas en un Plan Integral en el que participan las distintas entidades y vecinos
} 
ría, habían sido ocupadas irregularmente. La negativa a este retorno está fundamentada en varias consideraciones, entre ellas, el criterio jurídico respecto a la ocupación de las viviendas, las dificultades de integración que plantean estas personas y los mínimos resultados obtenidos en cuanto a convivencia vecinal; todas entendidas como importantes lastres para el desarrollo del Plan Integral. Dice el comunicado en el punto cuarto:

"Todos los responsables y técnicos, avalados por la experiencia adquirida en los procesos de intervención social en zonas marginales, somos conscientes de no poder lograr mínimos resultados de convivencia e integración en aquellos casos en los que familias, muy numerosas, de forma masiva y sin ningún proceso previo de adquisición de hábitos sociales de convivencia comunitaria, irrumpen en un núcleo de viviendas con puertas comunes interiores y procedentes de modos y costumbres de vida propias de núcleos chabolistas". Continúa el texto... "El propio informe de los Equipos y entidades que, desde los años anteriores, hicieron el seguimiento y el proceso de integración de estas cuarenta familias corroboran esta valoración afirmando, rotundamente, que no es posible lograr hábitos de socialización de forma „reagrupada" sino individualizada, caso por caso, en zonas/barrios distintos, y en más de la mitad de ellas, previo instancias intermedias de aprendizaje".

A diferencia de la posición adoptada por el Comisionado, la delegación sevillana de la Asociación Pro-Derechos Humanos de Andalucía, cuyo comunicado correspondiente fue confeccionado algún tiempo antes, concretamente el 15 de junio de 2009, denunciaba el abandono insoportable de estas personas así como el incumplimiento de algunos derechos básicos, entre ellos el de la seguridad de las mismas. Juzgando "lamentable y vergonzosa" la actuación de las administraciones públicas. La APDHA-Sevilla, centraba su queja en el hecho de que estas personas pierdan el derecho de propiedad sobre las viviendas en las que han residido 5 años, dice el propio texto:

(...) "Tampoco es aceptable que estas mismas personas pierdan el derecho a una propiedad que compraron en las condiciones que el mercado y el Ayuntamiento de Sevilla les impusieron y que ahora se les reclamen títulos de propiedad; cuando se les entregó una cantidad irrisoria para que resolvieran por su cuenta el problema de la vivienda, era de todos conocido que sólo podían hacerlo en las condiciones que al final lo hicieron. Las mismas condiciones en las que viven miles de sevillanos en barrios marginados, como Los Pajaritos, Torreblanca o el Polígono Sur pero que gozan de un estatus de respeto un poco mayor por parte de las instituciones, al punto de que nadie pondría en duda la propiedad de su casa, independientemente de que hayan hecho las transacciones para adquirirlas al margen de la ley".

Es interesante, y curioso, que ambos comunicados remitan, aunque con desigual nivel de detalle, a los errores políticos cometidos años atrás para explicar el origen del problema, y compartan además los procedimientos que deben orientar la intervención con poblaciones chabolistas, es decir, introducen y concluyen el comunicado con las mismas apreciaciones; sin embargo, divergen en uno de los asuntos nucleares de la cuestión. Mientras que la APDHA-Sevilla observa el derecho de estas familias a volver a las viviendas, destacando en su denuncia el estado de abandono e inseguridad que sufren, el Comisionado del Polígono Sur resalta los conflictos que podría generar su regreso y el interés por la seguridad interna del barrio, entendiendo éste como un espacio urbano delimitado sujeto a un proyecto transformador del que se siente responsable y cuya viabilidad podría comprometerse con la 
vuelta de estas trescientas personas.

Sin entrar en las contradicciones que emergen en estos enfoques y posicionamientos, valoramos las justificaciones ofrecidas como una muestra sintomática de las múltiples variables que intervienen en esta problemática. En ella queda expresada la gravedad de estos sucesos concretos -comenzando por el abandono y desprotección de las personas que han salido del barrio- y se ponen de relieve otros aspectos que trascienden incluso la cuestión chabolista, remitiendo al grado de marginalidad de espacios como Polígono Sur y a los procesos de transformación que en él tratan de llevarse a cabo. Si bien, como decíamos en epígrafes anteriores, el abandono del hábitat marginal es fundamental para el proceso de integración social de las poblaciones chabolistas, los escasos resultados que en esta dirección se han obtenido con las familias procedentes de Bermejales corroboran la importancia que tienen las formas en que no deben producirse determinadas intervenciones.

Por otro lado, parecen confirmarse en gran medida las aseveraciones, expresadas al comienzo del artículo, en las que planteábamos el fenómeno chabolista como una representación de determinadas desigualdades sociales y dinámicas de segregación territorial, reiteramos en este sentido que se trata de una consecuencia de las desequilibradas estructuras sociales y laborales que persisten; esta forma de hábitat marginal constituye una referencia "de apoyo" dentro de las dinámicas de integración/exclusión social; es un continuo reto político que no encuentra, por lo general, respuestas adecuadas. Además, algunos barrios consolidados pero muy desfavorecidos, pueden contener manifestaciones encubiertas de un chabolismo efectivo ("vertical") así como de un chabolismo latente o potencial.

\section{Algunas conclusiones}

Los poblados chabolistas existentes en Sevilla, de distintos tamaños y arraigo o estabilidad, son una muestra de la complejidad inherente a este fenómeno situado en la marginación y de la dificultad que pueden tener las administraciones públicas a la hora de evitar su formación y para erradicarlos una vez establecidos. El hábitat precario y degradado que los caracteriza y las situaciones de vulnerabilidad y exclusión social que los definen, son circunstancias que enmarcamos en el contexto de la desigualdad urbana general -y por tanto entendemos que debemos relacionarlas con ella- y, tal como señalan algunos autores, con unas desiguales estructuras sociales y laborales persistentes. Todo ello, unido a la estigmatización y a las carencias de los planteamientos y medidas institucionales que tratan de enfrentarlo, explica la gran complejidad a la que aludimos.

El análisis de la casuística sevillana en las dos últimas décadas, nos permite además corroborar las múltiples aristas del fenómeno. Su carácter marginal está indisolublemente unido, desde distintos puntos de vista, a su indefinición o ambigüedad: a nivel conceptual genera dudas si determinados alojamientos precarios se ajustan o no a las determinaciones jurídicas de la infravivienda; por otro lado, la eventualidad inicial de algunos poblados se apoya también en su indefinición administrativa, situándose en espacios fronterizos entre distintas administraciones (en espacios intermunicipales generalmente) u organismos que puedan sentir responsabilidad al respecto. Estas contradicciones, surgidas en diferentes planos, también pueden emerger para explicar la perpetuidad de un espacio chabolista. En este sentido, el caso del Vacie ha podido servirse, a un mismo tiempo, del aislamiento generado por su emplazamiento periférico original -situación que, si bien permanece negativamente 
connotada por la ubicación del cementerio, ha cambiado significativamente en los últimos veinte años- y las posibilidades que le otorga esa ubicación para disponer de algunos servicios. Sea como fuere, El Vacie en Sevilla, inserto actualmente en un proceso de desmantelamiento y realojos del que desconocemos los resultados que se van obteniendo, es representativo de una dialéctica socio-espacial que consideramos fundamental en todos estos enclaves: las condiciones de vida de sus pobladores se relacionan con hábitos de comportamiento difícilmente corregibles si no se desvinculan del entorno físico chabolista en el que se desarrollan.

Las dificultades antes apuntadas para la intervención y transformación de estas situaciones, quedan aquí ejemplificadas en la descripción e interpretación de tres operaciones llevadas a cabo entre los años noventa (actuación en San DiegoLos Carteros) y la pasada década (actuaciones en Perdigones y Bermejales). La conclusión que puede desprenderse nos hace reparar en la importancia de una verdadera comprensión del fenómeno en todas sus dimensiones, en la necesidad de responder de un modo específico a situaciones que son realmente singulares, y en la relevancia de establecer un procedimiento bien planificado en el que, mucho más allá del objetivo de conseguir liberar el suelo correspondiente -objetivo que rechazamos por su relación con los intereses urbanísticos especulativos-, prevalezca un proceso de realojamiento ordenado y diseñado acorde con las características y posibilidades de las familias instaladas en el poblado. En este sentido, el acompañamiento social, antes, durante y después de tales operaciones parece fundamental. Asimismo, resulta también imprescindible conocer si las reubicaciones pueden producirse a partir de criterios de dispersión, el modo de acceso factible y aconsejable a los nuevos alojamientos y si el entorno de acogida puede ejercer efec- tivamente dinámicas de integración social.

\section{Referencias}

CARABALLO, Rosario. Construyendo Nuestro Barrio. San Diego, El Comienzo de un Trabajo Juntos. Ed. Asociación de Vecinos "Andalucía" de San Diego, Sevilla, 1999. 130 p.

CORTÉS, Luis. Vivienda y exclusión residencial. En AGUILAR, M.; LAPARRA, M. y PÉREZ, B.C. (Eds.). Investigaciones de base para la elaboración del Plan de Lucha contra la exclusión social en la Comunidad de Madrid. Dirección General de Servicios Sociales, Comunidad de Madrid, 2003, p. 332-477.

DEFENSOR DEL PUEBLO ANDALUZ. Chabolismo en Andalucía. Informe Especial. Presentado en el Parlamento de Andalucía el 15-122005 y publicado en el BOPA $n^{\circ} 377$, de $14-02-$ 2006, VII Legislatura. 258 p.

$<$ http://www.defensor-

and.es/informes_y_publicaciones/informes_estu dios_y_resoluciones/informes_especiales/inform e_0004/TEXTO_PAGINADO/index.html>. (Consultado el 1 de septiembre de 2009).

GAMELLA, Juan Francisco. La población gitana en Andalucía. Un estudio exploratorio de sus condiciones de vida, Ed. Consejería de Trabajo y Asuntos Sociales, Junta de Andalucía, 1996.

GONZÁLEZ DORADO, Antonio. Sevilla: Centralidad Regional y Organización Interna de su Espacio Urbano. Ed. Área de Cultura y Fiestas Mayores, Ayuntamiento de Sevilla (2 ${ }^{\mathrm{a}}$. Edición), 2001.540 p.

IZQUIERDO, Rosario-ASOCIACIÓN DE ESTUDIOS SOCIALES POR LA IGUALDAD DE LA MUJER. Las mujeres de la Zona Norte: exclusión social y género en el norte de Sevilla. Ed. Observatorio de la Calidad del Empleo, Ayuntamiento de Sevilla, 2006. 189 p.

LAGO, María Jesús. Marginalidad residencial y exclusión social. La situación de los chabolistas 
madrileños. En TEZANOS, José Félix (Ed.). Tendencias en desigualdad y exclusión social. Tercer foro sobre tendencias sociales. Editorial Sistema, Madrid, 2004, pp. 737-776.

OFICINA DEL PLAN DE SEVILLA. Estrategias para la cohesión urbana. Documento de oportunidades y estrategias para la ordenación urbana-territorial de Sevilla. En Nuevo Plan General Municipal de Ordenación. Oficina del Plan de Sevilla, Ayuntamiento de Sevilla, 2006.

TORRES GUTIÉRREZ, Francisco José. Segregación urbana y exclusión social en Sevilla. El paradigma Polígono Sur. Área de Análisis Geográfico Regional, Universidad Pablo de Olavide, 2009. Tesis doctoral inédita actualmente en trámite de publicación por parte del Servicio de Publicaciones de la Universidad de Sevilla.

\section{Fuentes en Prensa escrita}

DIARIO DE SEVILLA, 24/11/2008: "Hacia el fin del Vacie. La Junta y el Ayuntamiento de Sevilla planifican la erradicación de las chabolas". Reportaje elaborado por Reyes Rincón.

DIARIO DE SEVILLA, 15/04/2009: “El realojo de las familias del Vacie se desarrollará en toda la ciudad”. Publicado por Noelia Márquez.

DIARIO DE SEVILLA, 27/07/2010: "Lipasam limpiará El Vacie a diario a partir de diciembre. Esta medida forma parte de la segunda fase del plan de normalización”. Publicado por R.S.

DIARIO DE SEVILLA, 08/06/2011: “CCOO y UGT temen despidos en la plantilla de Bienestar Social. Los sindicatos piden que no haya recortes en los servicios que atienden barrios como $\mathrm{El}$ Vacie". Publicado por A.S. Ameneiro.

DIARIO DE SEVILLA, 08/07/2011: "Una oportunidad para el Vacie. El Ayuntamiento avanza en las tareas de limpieza y comienza hoy a adecentar con gravilla los caminos del poblado chabolista”. Publicado por Noelia Márquez.

DIARIO DE SEVILLA, 16/09/2011: "El plan especial del Vacie y otras zonas marginadas sufrirá un drástico recorte. El Ayuntamiento, que culpa a la retirada de fondos por parte de la Junta, reducirá el horario y el salario de los trabajadores". Publicado por M.B.

EL PAÍS-ANDALUCÍA, 09/08/2009: “Un drama de integración, éxodo y abandono. Las administraciones no han sabido reaccionar ante una situación extrema”. Publicado por Ángeles Lucas.

\section{Cita del artículo}

TORRES, F.J. El territorio de los desheredados. Asentamientos chabolistas y experiencias recientes de erradicación en Sevilla. Hábitat y Sociedad, 2011, n³, p. 67-90.

<www.habitatysociedad.us.es>.

http://dx.doi.org/10.12795/HabitatySociedad.2011.i3.05 